\title{
Regression of cirrhosis-my current understanding
}

\begin{abstract}
The anatomical and histo pathological state of chronic liver diseases is a balance between the effects of liver injury and repair. As cirrhosis develops and progress the fibrous bands tends to be thick and widened with evidence of histological activity and Cirrhosis is more of a macro nodular pattern. If the cause of ensuing liver injury is removed or if effective treatment of underlying liver injury diseases are ensured, regeneration of hepatocytes dominates over fibrosis resulting enlargement of regenerative nodules and expansion against septae as well as lyses of sepate. Nodules surrounded by thin sepate then coalesce first giving rise to macro nodular pattern cirrhosis. Incomplete septal cirrhosis is morphological land mark in this dynamic process of regeneration and repair and thus these authors postulate that incomplete cirrhosis is a feature of regressing cirrhosis rather than a separate entity as it was told by Poper H.1
\end{abstract}

Keywords: histopathological sub classification of cirrhosis, regression of cirrhosis, histological criteria of regression of cirrhosis, incomplete cirrhosis
Volume 5 Issue 2 - 2017

\author{
Pranab kumar Bhattacharya,' Sumona \\ Mukherjee,' Suvodeep Panda,' Ritwick \\ Bhattacharya,' Dalia Mukherjee,' Debasis \\ Mukherjee,' Hindole Banerjee,' Runa Mitra,' \\ Rupak Bhattacharya, ${ }^{2}$ Upasana Bhattacharya, \\ Rupsa Bhattacharya,' Ayishi Mukherjee' \\ 'University of Calcutta, India \\ ${ }^{2}$ University Jadavpur, India
}

Correspondence: Pranab Kumar Bhattacharya, Professor of Pathology, Murshidabad Medical college, University of Calcutta, Berhampore station road, Berhampore Court, Murshidabad, West Bengal, India, Tel 923I510435, Email profpkb@yahoo.co.in

Received: July 12, 2017 | Published: November 08, 2017
Abbreviations: HVPG, hepatic venous pressure gradient; EVG, elastic vangesion stain; $\mathrm{HCV}$, hepatitis c virus ; HBV, hepatitis b virus

\section{Introduction}

Cirrhosis is defined as a diffuse process characterized by fibrosis and the conversion of normal liver architecture into structurally \&functionally abnormal nodule. A new patho physiological relevant definition of cirrhosis state and cirrhosis is the collection of anatomic changes in the liver that results from presence of wide spread imbalance of hepatic blood flow where inflow exceeds the outflow capacity .In cirrhosis fibrous septea develops when there is formation of parechymal extinction lesions with loss of contagious hepatocytes. Parenchymal extinction lesions accumulates to form confluent regions of extinctions that results in morphological pattern recognizable of cirrhosis. Activation of hepatic fibroblasts is mediated mainly by inflammatory or congestive mechanism. So Cirrhosis becomes the end stage of liver fibrosis and it results from a variety of chronic liver insults we know, which includes, congenital, metabolic, toxic, inflammatory and various infective causes and cirrhosis leads to complete morphologic alteration of liver and switch from lobular to a nodular organization associated with vascular remodeling \& biochemical changes

\section{Clinical staging of cirrhosis}

Clinical Staging of Cirrhosis is based on the factors that predict death. The utility of clinical sub classification is meant mainly for identification of patients who will require liver transplant. Broadly clinically Cirrhosis have been classified as I) Compensated cirrhosis II) De-compensated cirrhosis. Now de-compensated cirrhosis is defined by the clinically detected ascities, varicial hemorrhage, hepatic encephalopathy with jaundice and all these complications results from portal hypertension and or liver cells functional insufficiency. The hepatic venous pressure gradient (HVPG) is used for sub classification and predictor of poor outcome. Advantage of HVPG is that a trans jugular liver biopsy can be obtained during the same procedure, which can help histological \& hemodynamic correlations.

\section{Histological sub-classification of cirrhosis}

Though liver biopsy is an invasive procedure and mostly today replaced by fibroscan, however it is still the gold standard for diagnose of liver disorders, for staging of chronic liver diseases and for establishing the diagnosis. Liver biopsy provides more information regarding patho physiology of the diseases and has added advantages that it can be reviewed retrospectively. Several histo pathological features have been evaluated to correlate with severity of chronic liver disease including cirrhosis. The three features which are most important and significant are nodule size, septal fibrosis and width to correlate with clinical outcome. With increasing severity of liver diseases, the amount of fibrosis increases and parenchymal mass of hepatocytes decreases. Along similar liver, a reported case of conversion from micro nodular to macro nodular cirrhosis are associated with clinical improvement. The Lannec group of expert liver pathologists first proposed classification of cirrhosis in the following manner-based or nodule size and septal thickness: ${ }^{2,3}$

i. Stage-4a: Definite or probable Cirrhosis, Thin Septa, one broad septum can be allowed.

ii. Stage-4b: At least two broad Septa, but no very broad septum.

iii. Stage-4c: At least one very broad septum or many minute nodules.

Septa are defined as broad when the thickness is equivalent the size of the small module and as very broad septa when the thickness is greater than the size of nodule. Laennec system of fibrosis \& staging of cirrhosis correlated with not only HVPG but also with severity of varies and ascities. In the Laennec system fibrosis septae are described as broad when the thickness is equivalent to the size of the nodule and very thick when the thickness is greater than the size of the nodule. However Nagula et al sub-classified cirrhosis, when they did study on 
chronic hepatitis $\mathrm{C}$ patients showed small nodules and thick septae were more likely to have HVPG greater than $10 \mathrm{~mm} \mathrm{Hg}$ pressure. $^{4}$ In their study they compared the size of the nodule to width of liver biopsy and showed that small nodules were less than $1 \mathrm{~mm}$, large nodules were greater than $2 \mathrm{~mm}$, thin septae were less than $0.2 \mathrm{~mm}$ and thick septae were greater than $0.4 \mathrm{~mm}$ and they devised a scoring system to categorize cirrhosis into Category A and Category B, based on nodule size and septal thickness.

\section{Most recent classification system}

The most recent classification was done by Jain Garcia ${ }^{5}$ where the histologic criteria had been better defined in more objective ways. The Jain-Garcia system that their author followed are based on different histological criteria to classify cirrhosis. For classification of cirrhosis the type of predominant ( $>2 / 3$ septa) or nodules in the biopsy is taken into account to classify, otherwise considered as mixed as it is given below Table 1.

Table I Classification of cirrhosis

\begin{tabular}{|c|c|c|}
\hline Nodule & Septa & Score \\
\hline $\begin{array}{l}\text { Large Nodule } \\
(>2 \mathrm{~mm})=1\end{array}$ & Thin septae $(<0.1 \mathrm{~mm})=3$ & $<4($ Stage $-4 a)$ \\
\hline $\begin{array}{l}\text { Mixed } \\
\text { Nodules }=2\end{array}$ & $\begin{array}{l}\text { Intermediate septae }(0.1- \\
0.2 \mathrm{~mm})=2\end{array}$ & 4(Stage 4b) \\
\hline $\begin{array}{l}\text { Small Nodules } \\
(<1 \mathrm{~mm})=3\end{array}$ & $\begin{array}{l}\text { Thick septae } \\
(>0.2 \mathrm{~mm})=4\end{array}$ & $>4($ Stage $4 c)$ \\
\hline
\end{tabular}

Collagen proportionate is important in sub classifying chronic liver disease for Hepatitis C patients to be done with Elastic Vangesion Stain (EVG) Stain or Sirius stain. Fibrosis is expressed as the area occupied by collagen as a proportion of total biopsy area referred as collagen proportionate area $^{6}$ and collagen proportionate area correlate well with clinically significant portal hypertension. This procedure is done by these authors by Sirus Red Stained sections using computer assisted digital imaging technology. ${ }^{7}$ However crude assessment of collagen can also be done by a well trained histopathologist in good in good bi ocular Microscope too.

\section{Why this sub classification required?}

There are evidences, both in animal models and in human that liver fibrosis and even cirrhosis can be regressed or completely revert to normal liver architecture and function, either on cessation of the cause of liver injury or treatment of the underlying cause. ${ }^{8}$ In 1979, there was a land mark published paper in journal Pathology Annual by Perez Tamzyao, who first described the evidence for reversal of fibrosis and cirrhosis in both animal model and in human. ${ }^{9}$ They demonstrated first that arrest of fibrogenic stimulus can cause reversion of liver fibrosis induced by $\mathrm{CCl} 4$ intoxications or bile duct ligation in rat models. We today know that following antiviral treatment of hepatitis B, a shift from fully developed hepatitis B induced cirrhosis to incomplete septal cirrhosis. The best demonstration of such reversibility of cirrhosis is demonstrated in patients with hepatitis $\mathrm{C}$ virus (HCV) or hepatitis $\mathrm{B}$ virus (HBV) cirrhosis treated effectively with drug sofusbuvir ${ }^{1-6}$ or with velpatasvir or with $\gamma$-interferon(peginterferon). In additions there are also several reports of histo pathological proof (Stage 4c cirrhosis) in auto Immune hepatitis, ${ }^{9}$ hereditary heamochromotosis, secondary briliary cirrhosis and occasional cases of wilson's disease. The morphological features of regressing cirrhosis in human have been defined above. Regression of cirrhosis involves two main processes, namely decrease in fibrosis and repopulation of fibrogenic region by regenerating hepatocytes. There is no decrease of amount fibrous tissue and collagen tissue which may be assessed by sirus red stain followed by computer assisted digital images or by vangision stain and reticulin stain followed by morphometric measurement of fibrous area. There will be thinning of fibrous septa with disappearance of shunting vessels where the septa and septa becomes incomplete gradually thinned out and finally disappear. Bile ductular proliferation will disappear quickly in a regressing liver where as sinusoidal capillaries proliferation and peri sinusoidal fibrosis become inconsistent regression of fibrosis is associated with partial or full restoration lobular organization. There are eight parameters which represent hepatic repair complex or regression of cirrhosis:

i. Perforated delicate septa.

ii. Isolated thick collagen fibers.

iii. Delicate peri portal fibrous spikes.

iv. Portal tract remnants.

v. Hepatic vein remnants with prolapsed hepatocytes

vi. Hepatocytes within portal tracts or split septa.

\section{A new concept of incomplete septal cirrhosis}

Histo pathologically different pattern of Cirrhosis can be described which depends on interplay between hepatocyte injury, regeneration and fibrosis. Morhphologically cirrhosis is usually termed micronodular or macro nodular or mixed type. There is another type of cirrhosis which was introduced by Popper $\mathrm{H}$ et al. as incomplete septal cirrohosis ${ }^{9}$ a type of macro nodular cirrhosis in which slender incomplete septae demarcate larger inconspicuous nodules. On needle biopsy of liver apart from then

i. Incomplete septa render.

ii. A vague nodule formation to the liver. Incomplete Septal cirrohosis is also associated.

iii. Hypoplastic Portal tract.

iv. Increase in venous channels.

v. Abnormal spacing between portal tracts and veins.

vi. Crowding of Reticulin fibers between adjacent zones of Hyperplastic Parenchyma

vii. Hepatocyte cell plate thickening

viii. Dilated Sinusiods, Regression of cirrohosis is best demonstrated in Chronic Hepatitis B and Chronic Hepatitis C after effective treatment with drug sofusbuvir ${ }^{1-6}$ or with velpatasvir, with or without Ribavirin or with $\gamma$-interferon (peginterferon).

Regression may be demonstrated also in Alcoholic cirrohosis in compensated state after abstinence of alcohol and with antifibrogenic drugs, Similarly Histopathological improvement between pared liver biopsies is also observed after weight loss, hypocaloric diet, Blood sugar control, control of hyperlipidimia and exercise in established NASH or NAFLD related cirrhosis . There are many reports of 
regression of cirrohosis in autoimmune hepatitis after treatment with prednisilone and Azothiaprine In contrast features of regressions have not been yet well established in primary billiary cirrhosis, primary sclerosing cholangitis and vascular obliterative disease.

\section{Progression versus regression assessment by pathologists}

As a pathologist while we authors evaluate liver biopsy from a case of established cirrhosis we must try to evaluate whether cirrhosis is progressive or regressive as per Wanless criteria ${ }^{10}$ This should be assessed in paired liver biopsies taken after significant time interval of complete treatment. A biopsy Length of at least $2-3 \mathrm{~cm}$ or presence of 11 complete portal tract are considered adequate liver biopsy for this purpose (Table 2).

Table 2 Adequate liver biopsy

\begin{tabular}{|c|c|c|}
\hline General & Progression & Regression \\
\hline Area & $\begin{array}{l}\text { Enlarged with chronic } \\
\text { inflammation \& fibrosis. }\end{array}$ & $\begin{array}{l}\text { Normal or enlarged, but } \\
\text { with fibrosis only. }\end{array}$ \\
\hline Bile ducts & Preserved or absent & Usually preserved \\
\hline $\begin{array}{l}\text { Hepatic } \\
\text { Artery }\end{array}$ & $\begin{array}{l}\text { May be prominent due to } \\
\text { formation of vascular shunts. }\end{array}$ & $\begin{array}{l}\text { Prominence of hepatic } \\
\text { arterioles persist. }\end{array}$ \\
\hline Portal Veins & $\begin{array}{l}\text { Obscured due to obliterative } \\
\text { venopathy. }\end{array}$ & Obscuring portal veins \\
\hline $\begin{array}{l}\text { Interface } \\
\text { Activity }\end{array}$ & $\begin{array}{l}\text { Frequently active interface } \\
\text { hepatitis, cholestasis, ductular } \\
\text { proliferation. }\end{array}$ & Inactive \\
\hline \multirow[t]{2}{*}{ Fibrous Septa } & $\begin{array}{l}\text { With or without bridging: } \\
\text { Pattern of septal fibrosis } \\
\text { depends on Etiology: broad } \\
\text { inflamed septa in case of viral } \\
\text { hepatitis }\end{array}$ & $\begin{array}{l}\text { Thinned delicate } \\
\text { (even bridging) may } \\
\text { exhibit. Discontinuity, } \\
\text { Perforation. }\end{array}$ \\
\hline & $\begin{array}{l}\text { More delicate sinusoidal } \\
\text { fibrosis in Alcohol, Toxic and } \\
\text { Metabolic conditions. }\end{array}$ & \\
\hline $\begin{array}{l}\text { Parenchymal } \\
\text { Hepatocytes }\end{array}$ & $\begin{array}{l}\text { May or may not show } \\
\text { characteristic histological } \\
\text { feature of Aetiology. }\end{array}$ & $\begin{array}{l}\text { May be residual feature } \\
\text { of underlying cause } \\
\text { present. }\end{array}$ \\
\hline $\begin{array}{l}\text { Hepatic } \\
\text { Cellular } \\
\text { Complex }\end{array}$ & Absent & Present \\
\hline
\end{tabular}

\section{Conclusion}

Cirrhosis of liver was considered an irreversible condition. However, many experimental findings and clinical studies have shown regression of cirrhosis is a possibility in some cases. Fibrosis has been implicated as a very important marker for the course of the disease. It is important to properly quantify fibrosis and look for other prognostic parameters in liver biopsies. The need of the hour is more clinical trials for interventions to regress cirrhosis, like antifibrotic agents developed in the light of a greater understanding of the pathophysiology of the cirrhotic process.

\section{Acknowledgements}

None.

\section{Conflicts of interest}

The author declares there are no conflicts of interest.

\section{References}

1. Poper H. What is the major types of Hepatic Cirrhosis in Ingel flinger Controversy in Internal Medicine Philadelphia. Relman A, et al. editors. Saunders Publishers, USA; 1966. p. 233-243.

2. Kutami R, Girgrah N, Wanless IR. The Laennec grading system for assessment of hepatic fibrosis: validation by correlation with wedged hepatic vein pressure as clinical feature. Heptalogy. 2000;32:407A.

3. Wanless IR, Sweeney G, Dhillon AP, et al. Lack of progressive hepatic fibrosis during long-term therapy with deferiprone in subjects with transfusion-dependent beta-thalassemia. Blood. 2000;100(5):1566-1569.

4. Nagula S, Jain D, Groszmann RJ. Histological-hemodynamic correlation in cirrhosis-a histological classification of the severity of cirrhosis. $J$ Hepatol. 2006;44(1):111-177.

5. Pierre Bedosa, Guadal Pepe, Garcia Tsao, et al. Cirrhosis Regression and Subclassification. Surg Pathol Clin. 2013;6(2):295-309.

6. Calvaruso V, Burroughs AK, Standish R, et al. Computer assessed Image analysis of Liver collagen: relationship to Ishak scoring and hepatic venous pressure gradient. Heptalogy. 2009;49(4):1236-1244.

7. Friedman SL, Bansal MB. Reversal of hepatic fibrosis-fact or fantasy? Hepatology. 2006;43(Supply 2):82-88.

8. Perez Tamzyo R. Cirrhosis of the Liver: a reversible disease? Pathol Annu. 1979;14(2):183-213.

9. Czaja AJ, Carpenter HA. Decreased fibrosis during Cortico Steroid Therapy of auto immune hepatitis. J Hepatol. 2004;40(4):646-652.

10. Wanless IR, Nakashime E, Shirman M. Regression of Human cirrhosis: Morphological Features and the genesis of incomplete septal cirrhosis. Arch Pathol Lab Med. 2000;124(11):1599-1607. 